\title{
Characteristics of patients dying within 30 days of diagnosis of breast or colorectal cancer in Scotland, 2003-2007
}

\author{
DH Brewster*,', DI Clark', DL Stockton', AJ Munro² and RJC Steele ${ }^{2}$ \\ 'Information Services Division, NHS National Services Scotland, Gyle Square, I South Gyle Crescent, Edinburgh EHI 2 9EB, UK; ${ }^{2}$ Department of Surgery \\ and Molecular Oncology, Ninewells Hospital and Medical School, Dundee DDI 95Y, UK
}

BACKGROUND: Recent research has shown that most of the excess risk of death following breast and colorectal cancer in England compared with Norway and Sweden occurs in older age groups during the first year, and especially in the first month of follow-up. The aim of this study was to explore the characteristics of patients dying within 30 days of being diagnosed with one of these cancers in Scotland during 2003-2007.

METHODS: Anonymised cancer registry records linked to hospital discharge and death records were extracted. The study population was divided into patients who died within 30 days of diagnosis (cases) and those who survived beyond this threshold (controls) Differences in patient-, tumour-, and health service-related characteristics were assessed using the $\chi^{2}$-test and logistic regression. RESULTS: Patients dying within 30 days were more likely to be elderly and to have experienced emergency admission to non-surgical specialities. Their tumours were less likely to have been verified microscopically, but they appeared more likely to be of high grade and advanced in stage. A substantial number of patients died from causes other than their cancer.

CONCLUSION: These results suggest that early mortality after a diagnosis of breast or colorectal cancer may be partly due to comorbidity and lifestyle factors, as well as due to more advanced disease. Further research is required to determine the precise explanation for these findings and, in particular, if any potentially avoidable factors such as delays in presentation, referral, or diagnosis exist.

British Journal of Cancer (201I) 1 04, 60-67. doi:I0.1038/sj.bjc.6606036 www.bjcancer.com

(c) 20II Cancer Research UK

Keywords: breast neoplasms; colorectal neoplasms; co-morbidity; mortality; Scotland; survival

Survival from major epithelial cancers appears to be lower in the United Kingdom than in the Nordic countries, with the interesting exception of Denmark (Sant et al, 2009). More detailed analyses suggest that most of the excess risk of mortality in the United Kingdom compared with the Nordic countries occurs within a year of diagnosis (Engholm et al, 2007; Thomson and Forman, 2009; Holmberg et al, 2010) and particularly within a month of diagnosis in older patients with breast cancer (Møller et al, 2010) or colorectal cancer (H Møller, personal communication). A popular interpretation, which underpins the National Awareness and Early Diagnosis Initiative in England (Department of Health, 2007), is that delays in presentation and/or referral, resulting in more advanced disease stage at diagnosis, are responsible for much of the survival deficit observed in patients with cancer in the United Kingdom. However, there are alternative explanations for the excess risk of early death. These include the following: increased comorbidity leading to increased operative risks; smoking, obesity, alcohol abuse, and other factors related to lifestyle, which might both increase surgical risks and limit options for non-surgical therapies; and socioeconomic deprivation, which has been

*Correspondence: Dr DH Brewster;

E-mail: David.Brewster@nhs.net, http://www.isdscotland.org/cancer Received 23 August 2010; revised 28 October 2010; accepted II November 2010 associated with increased risk of early death, although the mediators of any such effect are undoubtedly complex.

The aim of this study was to examine the characteristics of patients with breast or colorectal cancer who die within 30 days of diagnosis, using health service data collected routinely and, using proxy indicators, to explore the influence of socioeconomic deprivation, co-morbidity, and lifestyle on outcome.

\section{MATERIALS AND METHODS}

Anonymised records relating to patients diagnosed with breast cancer (ICD-10 C50) or colorectal cancer (C18-C20) during the period 2003-2007 were extracted from the Scottish Cancer Registry (SCR). Patients registered on the basis of a death certificate only were excluded ( $<1 \%$ of cases for both cancer sites). Only the first breast or colorectal cancer arising in an individual was included in the analysis.

Patient-, tumour-, and health service-related variables from the SCR were supplemented with variables derived from a permanently linked database of acute hospital discharge records, cancer registrations, and mortality records (Kendrick and Clarke, 1993). These supplementary variables included the following: any hospital admission with chronic obstructive pulmonary disease (COPD) in the 10 years preceding diagnosis of breast/colorectal cancer as a very crude proxy for smoking history; any hospital 
admission with alcohol-related diagnoses in the 10 years preceding diagnosis of breast/colorectal cancer; the number of hospital in-patient bed days in the period of 10 years up to 1 year preceding diagnosis of breast/colorectal cancer (as a crude indicator of general preexisting comorbidity); the number of emergency admissions to hospital in the 30 days either before or after diagnosis of breast/colorectal cancer; and place of death (from the full mortality record) for deceased patients. The diagnostic codes used to identify COPD and alcohol-related diagnoses are shown in Appendix 1. On the basis of the postcode of residence at the time of diagnosis, patients were assigned to a deprivation fifth using the Scottish Index of Multiple Deprivation (Scottish Government, 2006). This has seven domains (income, employment, education, housing, health, crime, and geographical access) at datazone level, which have been combined into an overall index to identify area concentrations of multiple deprivation.

Mode of presentation was investigated by examining the SCR 'method of first detection' variable, and the type of admission, speciality, and main diagnosis leading to hospital admission in the first hospital episode of the continuous in-patient stay, during which time the cancer was first mentioned on a hospital discharge record (restricted to admissions for the cancer occurring within 30 days of either side of the SCR incidence date).

The study population was divided into patients who died within 30 days of incidence/diagnosis (cases) and those who survived beyond this threshold (controls). Follow-up was until the end of 2008.

For each characteristic examined, the $\chi^{2}$-test of association was used to assess differences in proportions between cases and controls. Logistic regression modelling was used to generate adjusted odds ratios and their $95 \%$ confidence intervals. Cause of death and place of death were not included as factors in the logistic regression model because, by definition, the period of follow-up differed between cases and controls.

\section{RESULTS}

The study included 36484 patients. The distribution of early deaths, later deaths, and percentage of the cohort alive at the end of follow-up according to cancer site is summarised in Table 1 . The proportion of early deaths was significantly higher in patients with colorectal cancer (6.6\%) compared with patients with breast cancer $(1.3 \% ; P<0.001)$. The difference in the percentage of each cohort alive at the end of follow-up (50.3\% for colorectal cancer; $79.3 \%$ for breast cancer) was also statistically significant $(P<0.001)$.

\section{Breast cancer}

The distribution of characteristics of cases and controls is shown in Table 2. On the basis of univariate analysis, patients dying within 30 days of diagnosis were significantly more likely to be elderly; to lie outside the least-deprived category; to spend more time in hospital in the 10 years before diagnosis; to have been previously admitted for COPD; to have had one or more emergency admissions in the 30 days around diagnosis; to have had their tumour diagnosed without histology; and to have received no active treatment within 30 days of diagnosis. A lower rate of microscopic verification resulted in higher proportions of pathology-derived variables with unknown values among cases, making interpretation difficult. However, there is some evidence that cases were more likely to present with advanced disease, and less likely to present with low-grade tumours or oestrogen receptor-positive tumours. Just under $66 \%$ of cases had their primary cause of death attributed to breast cancer, and just over $70 \%$ of cases died in hospital.

The results of logistic regression modelling are shown in Table 3. Interactions were considered between age with other covariates, and stage with other covariates, and only inclusion of an interaction between age and the emergency admission variable resulted in a better-fitting model. After adjustment for covariates, the following factors remained predictive of death within 30 days of diagnosis: age group, deprivation category, emergency admissions, microscopic verification status, tumour stage, tumour grade, and absence of any recorded treatment within 30 days of diagnosis.

Of the 249 patients dying within 30 days of diagnosis of breast cancer, the 'method of first detection' was recorded as incidental finding in $47(18.9 \%)$ cases, clinical presentation with relevant symptoms or signs in $153(61.4 \%)$ cases, incidental finding at autopsy, previously unsuspected in $6(2.4 \%)$ cases, 'other' in 19 $(7.6 \%)$ cases, and not known in $24(9.6 \%)$ cases. No cases were recorded as screen detected or interval cancers.

Only $155(62.2 \%)$ cases and $11268(58.8 \%)$ controls had a hospital discharge record mentioning breast cancer with admission occurring within 30 days of the SCR incidence date. First admission to these continuous in-patient stays was recorded as emergency in $134(86.5 \%)$ cases compared with $866(7.7 \%)$ controls. Only $44(28.4 \%)$ of these 155 cases were first admitted under general surgery, compared with 9916 (88\%) of 11268 controls. A total of $87(56.1 \%)$ cases were first admitted under general medicine, a related subspeciality, or medicine for the elderly. Breast cancer was recorded as the primary diagnosis (main condition) in $91(58.7 \%)$ cases compared with 10635 (94.4\%) controls.

\section{Colorectal cancer}

The distribution of characteristics of cases and controls is shown in Table 4. On the basis of univariate analysis, patients dying within 30 days of diagnosis were significantly more likely to be elderly; to lie outside the least-deprived category; to have spent more time in hospital in the 10 years before diagnosis; to have been previously admitted for COPD; to have had previous alcoholrelated admissions; to have had one or more emergency admissions in the 30 days around diagnosis; to have had their tumour diagnosed without histology; and to have received no active treatment within 30 days of diagnosis. As for breast cancer, a lower rate of microscopic verification resulted in higher proportions of pathology-derived variables with unknown values among the cases, making interpretation difficult. However, there is some evidence that cases were more likely to present with advanced disease and possibly less likely to present with lowgrade tumours. Cases were less likely to have tumours of the rectum or rectosigmoid, although around a quarter of them did not have a tumour subsite specified. The male/female ratio was 1.2 among controls, but 1.0 among cases. Just under $73 \%$ of cases had their primary cause of death attributed to colorectal cancer, and just over $82 \%$ of cases died in hospital.

The results of logistic regression modelling are shown in Table 5. Interactions were considered between age with other covariates and Dukes' stage with other covariates. Inclusion of interactions for age and the emergency admission variable, age and microscopic verification status, age and any treatment variable, and Dukes' stage and treatment resulted in a better-fitting model. After adjustment for covariates, the following factors remained predictive of death within 30 days of diagnosis: age group, deprivation category, previous in-patient bed days, previous admissions for COPD, previous alcohol-related admissions, emergency admissions, microscopic verification status, tumour subsite, Dukes' stage, tumour grade, and treatment within 30 days of diagnosis. The relationship between treatment and outcome was complex: stage $\mathrm{A}, \mathrm{B}$, or $\mathrm{C}$ cases were more likely to have received treatment within 30 days than were controls, whereas stage ' $D$ ' or unstaged cases were less likely to have received treatment.

Of the 1129 patients dying within 30 days of diagnosis of colorectal cancer, the 'method of first detection' was recorded as screening examination in one $(0.1 \%)$ case, incidental finding in 22 $(1.9 \%)$ cases, clinical presentation with relevant symptoms or signs 
Table I Distribution of early deaths, later deaths, and percentage of the cohort alive at the end of follow-up, stratified by cancer site

\begin{tabular}{|c|c|c|c|c|c|c|c|}
\hline \multirow[b]{2}{*}{ Cancer site } & \multirow[b]{2}{*}{ All } & \multirow[b]{2}{*}{ Died within 30 days } & \multirow[b]{2}{*}{$\%$} & \multicolumn{3}{|c|}{ Survived beyond 30 days } & \multirow[b]{2}{*}{$\%$ of cohort alive at the end of 2008} \\
\hline & & & & Total & Alive & Dead & \\
\hline Colorectal & 17075 & 1129 & 6.6 & 15946 & 8582 & 7364 & 50.3 \\
\hline
\end{tabular}

Table 2 Characteristics of patients dying within 30 days of diagnosis of breast cancer in Scotland; period of diagnosis 2003-2007

\begin{tabular}{|c|c|c|c|c|c|}
\hline \multirow[b]{2}{*}{ Characteristic } & \multicolumn{2}{|c|}{ Cases } & \multicolumn{2}{|c|}{ Controls } & \multirow[b]{2}{*}{$P$-value } \\
\hline & Number & $\%$ & Number & $\%$ & \\
\hline \multicolumn{5}{|l|}{ Age group } & $<0.001$ \\
\hline$<65$ & 35 & $|4|$. & 10676 & 55.7 & \\
\hline $65-74$ & 49 & 19.7 & 4212 & 22.0 & \\
\hline $75-79$ & 41 & 16.5 & 1614 & 8.4 & \\
\hline $80-84$ & 48 & 19.3 & 1374 & 7.2 & \\
\hline $85+$ & 76 & 30.5 & 1284 & 6.7 & \\
\hline \multicolumn{5}{|l|}{ SIMD fifth ${ }^{\mathrm{a}}$} & 0.013 \\
\hline I-Least deprived & 28 & 11.2 & 3887 & 20.3 & \\
\hline 2 & 55 & 22.1 & 4008 & 20.9 & \\
\hline 3 & 60 & 24.1 & 4023 & 21.0 & \\
\hline 4 & 57 & 22.9 & 3880 & 20.3 & \\
\hline 5-Most deprived & 49 & 19.7 & 3358 & 17.5 & \\
\hline \multicolumn{5}{|l|}{ Previous inpatient bed days } & $<0.001$ \\
\hline 0 & || $\mid$ & 44.6 & $777 \mid$ & 40.6 & \\
\hline $1-7$ & 48 & 19.3 & 6431 & 33.6 & \\
\hline $8-28$ & 40 & $|6|$. & 3408 & 17.8 & \\
\hline $29+$ & 50 & 20.1 & 1550 & 8.1 & \\
\hline \multicolumn{5}{|l|}{ Previous admission for COPD } & $<0.001$ \\
\hline Yes & 19 & 7.6 & 462 & 2.4 & \\
\hline No & 230 & 92.4 & 18698 & 97.6 & \\
\hline \multicolumn{5}{|l|}{ Previous alcohol-related admission } & 0.157 \\
\hline Yes & 8 & 3.2 & 369 & 1.9 & \\
\hline No & 241 & 96.8 & | 879 | & 98.1 & \\
\hline \multicolumn{5}{|c|}{ Emergency admissions within 30 days of diagnosis date } & $<0.001$ \\
\hline 0 & $77^{\circ}$ & 30.9 & 17732 & 92.5 & \\
\hline$\geqslant 1$ & 172 & 69.1 & 1428 & 7.5 & \\
\hline \multicolumn{5}{|l|}{ Microscopically verified } & $<0.001$ \\
\hline Yes & 134 & 53.8 & 18943 & 98.9 & \\
\hline No & 103 & 41.4 & 196 & 1.0 & \\
\hline Not known & 12 & 4.8 & 21 & 0.1 & \\
\hline \multicolumn{5}{|l|}{ Tumour stage } & $<0.001^{b}$ \\
\hline l & 14 & 5.6 & 6710 & 35.0 & \\
\hline$\|$ & 10 & 4.0 & 7783 & 40.6 & \\
\hline III & 8 & 3.2 & 1506 & 7.9 & \\
\hline IV & 56 & 22.5 & 648 & 3.4 & \\
\hline Not known & 161 & 64.7 & 2513 & 13.1 & \\
\hline \multicolumn{5}{|l|}{ Tumour grade } & $<0.001^{c}$ \\
\hline I & 3 & 1.2 & 2343 & 12.2 & \\
\hline$\|$ & 23 & 9.2 & 7536 & 39.3 & \\
\hline III & 23 & 9.2 & 6441 & 33.6 & \\
\hline Not known & 200 & 80.3 & 2840 & 14.8 & \\
\hline \multicolumn{5}{|l|}{ ER status } & $<0.001^{d}$ \\
\hline Positive & 73 & 29.3 & 14668 & 76.6 & \\
\hline Negative & 22 & 8.8 & 3024 & 15.8 & \\
\hline Not known & 154 & 61.8 & 1468 & 7.7 & \\
\hline \multicolumn{5}{|c|}{ Any treatment within 30 days of diagnosis } & $<0.001$ \\
\hline Yes & 57 & 22.9 & 12880 & 67.2 & \\
\hline No & 192 & 77.1 & 6280 & 32.8 & \\
\hline
\end{tabular}

Table 2 (Continued)

\begin{tabular}{|c|c|c|c|c|c|}
\hline \multirow[b]{2}{*}{ Characteristic } & \multicolumn{2}{|c|}{ Cases } & \multicolumn{2}{|c|}{ Controls } & \multirow[b]{2}{*}{$P$-value } \\
\hline & Number & $\%$ & Number & $\%$ & \\
\hline Underlying cause of death & & & & & 0.092 \\
\hline Breast cancer & 163 & 65.5 & 2350 & 62.2 & \\
\hline Other cancer & 10 & 4.0 & 298 & 7.9 & \\
\hline Diseases of circulatory system & 40 & 16.1 & 572 & 15.1 & \\
\hline Diseases of respiratory system & 15 & 6.0 & 158 & 4.2 & \\
\hline Any other cause & 21 & 8.4 & 400 & 10.6 & \\
\hline Place of death ${ }^{\mathrm{e}}$ & & & & & $<0.001$ \\
\hline NHS acute hospital & 179 & 71.9 & 1951 & 51.8 & \\
\hline Home & 37 & 14.9 & 746 & 19.8 & \\
\hline Hospice & 7 & 2.8 & 477 & 12.7 & \\
\hline Other institution & 26 & 10.4 & 594 & 15.8 & \\
\hline
\end{tabular}

Abbreviations: $\mathrm{COPD}=$ chronic obstructive pulmonary disease; $\mathrm{ER}=$ oestrogen receptor; $\mathrm{SIMD}=$ Scottish index of multiple deprivation. ${ }^{\mathrm{a}} \mathrm{SIMD}$ not known for four controls. ${ }^{b} P<0.00$ I excluding not known category. ${ }^{c} P=0.222$ excluding not known category. ${ }^{d} P=0.118$ excluding not known category. ${ }^{e}$ Place of death not known for 10 controls.

in $937(83.0 \%)$ cases, incidental finding at autopsy, previously unsuspected in $20(1.8 \%)$ cases, 'other' in $61(5.4 \%)$ cases, and not known in $88(7.8 \%)$ cases. No cases were recorded as interval cancers.

Only $858(76.0 \%)$ cases and $10609(66.5 \%)$ controls had a hospital discharge record mentioning colorectal cancer, with admission occurring within 30 days of the SCR incidence date. First admission to these continuous in-patient stays was recorded as emergency in $685(79.8 \%)$ cases compared with $3881(36.6 \%)$ controls. Only $495(57.7 \%)$ of these 858 cases were first admitted under general surgery, compared with 7536 (71.0\%) of 10609 controls. A total of $276(32.2 \%)$ cases were first admitted under general medicine, a related subspeciality, or medicine for the elderly. Colorectal cancer was recorded as the primary diagnosis (main condition) in $620(72.3 \%)$ cases compared with 9401 $(88.6 \%)$ controls.

\section{DISCUSSION}

The main strengths of our study are the large number of patients included (over 36000) and the availability of information for a geographically defined population with universal health care and complete coverage by cancer registration. The study should include the same unselected spectrum of patients included in successive iterations of the EUROCARE survival studies. Identifying the population dying within 30 days is crucially dependent on the definition of diagnosis or incidence date. Unlike many cancer registries that choose from a hierarchy of dates dependent on the timing of microscopic verification, the SCR applies a definition published previously by the International Agency for Research on Cancer (MacLennan, 1991). Essentially, this allocates the earliest available date from a list of options, irrespective of microscopic verification status. In practice, this is usually the date of first relevant hospital contact for the cancer.

At first sight, the relatively low proportion of cases and controls with relevant hospital discharge records occurring within 30 days 
Table 3 Results of multivariable logistic regression model for breast cancer showing characteristics predictive of death within 30 days of diagnosis

\begin{tabular}{|c|c|c|c|c|}
\hline Characteristic & $\begin{array}{l}\text { Odds } \\
\text { ratio }\end{array}$ & $95 \%$ & $\begin{array}{l}\text { dence } \\
\text { al }\end{array}$ & $P$-value \\
\hline \multicolumn{5}{|l|}{ Age group } \\
\hline$<65$ & 1.00 & & & \\
\hline $65-74$ & 2.72 & 1.06 & 6.96 & 0.037 \\
\hline $75-79$ & 6.93 & 2.87 & 16.76 & $<0.001$ \\
\hline $80-84$ & 6.34 & 2.52 & 15.98 & $<0.001$ \\
\hline $85+$ & 8.70 & 3.80 & 19.88 & $<0.001$ \\
\hline \multicolumn{5}{|l|}{ SIMD fifth } \\
\hline I-Least deprived & 1.00 & & & \\
\hline 2 & 1.47 & 0.86 & 2.51 & 0.154 \\
\hline 3 & 1.96 & 1.15 & 3.31 & 0.013 \\
\hline 4 & 1.17 & 0.69 & 1.99 & 0.563 \\
\hline 5-Most deprived & 1.05 & 0.61 & 1.80 & 0.861 \\
\hline \multirow{2}{*}{\multicolumn{5}{|c|}{$\begin{array}{l}\text { Emergency admissions within } \\
30 \text { days of diagnosis date }\end{array}$}} \\
\hline & & & & \\
\hline 0 & 1.00 & & & \\
\hline$\geqslant 1$ & 26.93 & 11.45 & 63.33 & $<0.001$ \\
\hline \multicolumn{5}{|l|}{ Microscopically verified } \\
\hline Yes & 1.00 & & & \\
\hline No & 6.76 & 4.64 & 9.83 & $<0.001$ \\
\hline Not known & 5.21 & 2.22 & 12.20 & $<0.001$ \\
\hline \multicolumn{5}{|l|}{ Tumour stage } \\
\hline 1 & 1.00 & & & \\
\hline$\|$ & 0.62 & 0.27 & 1.42 & 0.254 \\
\hline III & 1.08 & 0.44 & 2.66 & 0.868 \\
\hline IV & 5.28 & 2.74 & 10.17 & $<0.001$ \\
\hline Not known & 3.55 & 1.95 & 6.48 & $<0.001$ \\
\hline \multicolumn{5}{|l|}{ Tumour grade } \\
\hline$|-1|$ & 1.00 & & & \\
\hline III & 3.20 & 1.99 & 5.13 & $<0.001$ \\
\hline Not known & 3.20 & 1.99 & 5.13 & $<0.001$ \\
\hline \multicolumn{5}{|l|}{$\begin{array}{l}\text { Any treatment within } \\
30 \text { days of diagnosis }\end{array}$} \\
\hline \multicolumn{5}{|l|}{30 days of diagnosis } \\
\hline Yes & 1.00 & & & \\
\hline No & 4.20 & 3.01 & 5.86 & $<0.001$ \\
\hline
\end{tabular}

Abbreviation: SIMD $=$ Scottish index of multiple deprivation. The interaction term age $\times$ emergency admissions was included in the model.

of the cancer registry incidence date seems surprising. However, there are a number of potential explanations for this. For example, in the case of elective referrals, the first relevant hospital contact (and, therefore, the source of the cancer registry incidence date) is likely to be an outpatient consultation - in some cases, the time to in-patient admission may have exceeded 30 days. In some cases, if patients are discharged from hospital before a pathology report is issued, the definitive diagnosis of cancer may not be recorded. The overall accuracy of main diagnosis on hospital discharge records is estimated to be around 88\% (Information Services Division, 2007); it follows that the diagnosis will inevitably be misclassified and/or miscoded in a proportion of cases.

The weaknesses of our study reflect the problems associated with relying on routinely collected data: for example, problems of attribution (of cause of death); problems of information completeness (lack of information on stage or histological grade for some tumours); and problems of surrogacy (the need to use diagnosis of COPD as a proxy for smoking status, or the use of number of hospital in-patient bed days as a proxy for comorbidity). In brief, we have obtained statistical power and representativeness at the expense of finer clinical details. The main weakness of our study is the absence of information on any delays in presentation, referral,
Table 4 Characteristics of patients dying within 30 days of diagnosis of colorectal cancer in Scotland; period of diagnosis 2003-2007

\begin{tabular}{|c|c|c|c|c|c|}
\hline \multirow[b]{2}{*}{ Characteristic } & \multicolumn{2}{|c|}{ Cases } & \multicolumn{2}{|c|}{ Controls } & \multirow[b]{2}{*}{$P$-value } \\
\hline & Number & $\%$ & Number & $\%$ & \\
\hline \multicolumn{5}{|l|}{ Age group } & $<0.001$ \\
\hline$<65$ & $|3|$ & 11.6 & 4602 & 28.9 & \\
\hline $65-74$ & 234 & 20.7 & 4884 & 30.6 & \\
\hline $75-79$ & 220 & 19.5 & 2793 & 17.5 & \\
\hline $80-84$ & 257 & 22.8 & 2138 & 13.4 & \\
\hline $85+$ & 287 & 25.4 & 1529 & 9.6 & \\
\hline \multicolumn{5}{|l|}{ Sex } & 0.002 \\
\hline Male & 564 & 50.0 & 8721 & 54.7 & \\
\hline Female & 565 & 50.0 & 7225 & 45.3 & \\
\hline \multicolumn{5}{|l|}{ SIMD fifth ${ }^{\mathrm{a}}$} & $<0.001$ \\
\hline I-Least deprived & 153 & 13.6 & 3046 & 19.1 & \\
\hline 2 & 210 & 18.6 & 3112 & 19.5 & \\
\hline 3 & 260 & 23.0 & 3347 & 21.0 & \\
\hline 4 & 264 & 23.4 & 3411 & 21.4 & \\
\hline 5-Most deprived & 242 & 21.4 & 3029 & 19.0 & \\
\hline \multicolumn{5}{|l|}{ Previous inpatient bed days } & $<0.001$ \\
\hline 0 & 338 & 29.9 & 5488 & 34.4 & \\
\hline $1-7$ & 257 & 22.8 & 5070 & 31.8 & \\
\hline $8-28$ & 269 & 23.8 & 3512 & 22.0 & \\
\hline $29+$ & 265 & 23.5 & 1876 & 11.8 & \\
\hline \multicolumn{5}{|l|}{ Previous admission for COPD } & $<0.001$ \\
\hline Yes & 134 & 11.9 & 831 & 5.2 & \\
\hline No & 995 & 88.1 & 15115 & 94.8 & \\
\hline \multicolumn{5}{|l|}{ Previous alcohol-related admission } & $<0.001$ \\
\hline Yes & 83 & 7.4 & 598 & 3.8 & \\
\hline No & 1046 & 92.6 & 15348 & 96.2 & \\
\hline \multicolumn{5}{|c|}{ Emergency admissions within 30 days of diagnosis date } & $<0.001$ \\
\hline 0 & 212 & 18.8 & 10108 & 63.4 & \\
\hline$\geqslant 1$ & 917 & 81.2 & 5838 & 36.6 & \\
\hline \multicolumn{5}{|l|}{ Microscopically verified } & $<0.001$ \\
\hline Yes & 666 & 59.0 & 15028 & 94.2 & \\
\hline No & 441 & 39.1 & 856 & 5.4 & \\
\hline Not known & 22 & 1.9 & 62 & 0.4 & \\
\hline \multicolumn{5}{|l|}{ Tumour sub-site } & $<0.001^{b}$ \\
\hline Proximal colon & 323 & 28.6 & 4912 & 30.8 & \\
\hline Distal colon & 258 & 22.9 & 4213 & 26.4 & \\
\hline Rectum/rectosigmoid & 258 & 22.9 & 5533 & 34.7 & \\
\hline Not known & 290 & 25.7 & 1288 & 8.1 & \\
\hline \multicolumn{5}{|l|}{ Dukes' stage } & $<0.001^{c}$ \\
\hline A & 17 & 1.5 & 1757 & 11.0 & \\
\hline$B$ & 97 & 8.6 & 4176 & 26.2 & \\
\hline C & 127 & 11.2 & 3893 & 24.4 & \\
\hline $\mathrm{D}$ & 371 & 32.9 & 2709 & 17.0 & \\
\hline Not known & 517 & 45.8 & 3411 & 21.4 & \\
\hline \multicolumn{5}{|l|}{ Tumour grade } & $<0.001^{d}$ \\
\hline I & 8 & 0.7 & $4 \mid 1$ & 2.6 & \\
\hline$\|$ & 264 & 23.4 & 8460 & 53.1 & \\
\hline III & 128 & 11.3 & 2186 & 13.7 & \\
\hline IV & 8 & 0.7 & 97 & 0.6 & \\
\hline Not known & 721 & 63.9 & 4792 & 30.1 & \\
\hline \multicolumn{5}{|c|}{ Any treatment within 30 days of diagnosis } & $<0.001$ \\
\hline Yes & 425 & 37.6 & 6876 & 43.1 & \\
\hline No & 704 & 62.4 & 9070 & 56.9 & \\
\hline Underlying cause of death & & & & & $<0.001$ \\
\hline Colorectal cancer & 822 & 72.8 & 5678 & 77.1 & \\
\hline Other cancer & 59 & 5.2 & 468 & 6.4 & \\
\hline
\end{tabular}


Table 4 (Continued)

\begin{tabular}{|c|c|c|c|c|c|}
\hline \multirow[b]{2}{*}{ Characteristic } & \multicolumn{2}{|c|}{ Cases } & \multicolumn{2}{|c|}{ Controls } & \multirow[b]{2}{*}{$P$-value } \\
\hline & Number & $\%$ & Number & $\%$ & \\
\hline Diseases of circulatory system & 114 & 10.1 & 678 & 9.2 & \\
\hline Diseases of respiratory system & 39 & 3.5 & 195 & 2.6 & \\
\hline Any other cause & 95 & 8.3 & 345 & 4.7 & \\
\hline Place of death ${ }^{\mathrm{e}}$ & & & & & $<0.001$ \\
\hline NHS acute hospital & 929 & 82.1 & 3691 & 50.2 & \\
\hline Home & 105 & 9.2 & 1895 & 25.8 & \\
\hline Hospice & 42 & 3.7 & 1233 & 16.8 & \\
\hline Other institution & 53 & 4.5 & 530 & 7.2 & \\
\hline
\end{tabular}

Abbreviations: $\mathrm{COPD}=$ chronic obstructive pulmonary disease; SIMD =Scottish index of multiple deprivation. ${ }^{\mathrm{a} S I M D}$ not known for one control. ${ }^{\mathrm{b}} \mathrm{P}<0.00 \mathrm{I}$ excluding not known category. ${ }^{C} P<0.001$ excluding not known category. ${ }^{d} P<0.001$ excluding

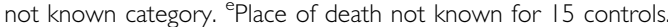

or diagnosis, as well as direct information on lifestyle risk factors. As a result, we are unable to determine whether patients dying early have advanced disease because of delays in presentation, referral, or diagnosis, or because of more aggressive disease, or both, and if there seem to be any avoidable factors contributing to their death. These questions can probably only be addressed by further research involving review of medical records. Indeed, at least some of the patients will already fall within the scope of the existing and well-established Scottish Audit of Surgical Mortality (Thompson and Stonebridge, 2005).

There are three main reasons for patients dying within a few weeks of the diagnosis of cancer: advanced, biologically aggressive disease by the time of diagnosis - death is directly due to the cancer itself; death due to complications related to treatment of the cancer - death is indirectly related to the cancer; and death due to some coincidental cause - death is not related to the cancer, either directly or indirectly. Any analysis of early deaths after the diagnosis of cancer has specifically to consider which of these reasons might apply. Earlier diagnosis of cancer might help prevent deaths in the first and second categories but would be unlikely to have any effect on the rate of intercurrent deaths. Conversely, comorbidity would have an impact on the second and third categories, but have limited impact on the first.

As expected, the overall mortality rate was higher in patients with colorectal cancer and the rate of early death was five times higher in patients with colorectal cancer. These findings reflect the differences in anatomy and the role of surgery in the two different types of tumour. Emergency surgery for breast cancer is an extreme rarity, whereas $20 \%$ of operations for colorectal cancer are classed as urgent or emergency procedures (Tekkis et al, 2003). Operative mortality is much higher for colorectal cancer than it is for breast cancer around $5 \%$ for elective colorectal surgery, up to $20 \%$ for emergency colorectal surgery (Tekkis et al, 2003), and less than $1 \%$ for breast cancer surgery (El-Tamer et al, 2007). These factors will account for the differences noted when Tables 2 and 4 are compared: only $23 \%$ of patients with breast cancer who died within 30 days of diagnosis had received any form of treatment for their tumour; the corresponding figure for patients with colorectal cancer was $38 \%$.

Unsurprisingly, multivariable analysis suggests that, compared with patients surviving beyond 30 days, patients with breast cancer dying early were more likely to be elderly; less likely to be affluent; more likely to have been admitted as an emergency within 30 days of diagnosis; less likely to have had their tumours microscopically verified; more likely to have advanced disease (or stage not known); more likely to have high-grade tumours (or grade not known); and less likely to have had any treatment within 30 days of diagnosis. Of the patients with breast cancer dying within 30 days, just over $34 \%$ were recorded as having an underlying cause of
Table 5 Results of multivariable logistic regression model for colorectal cancer showing characteristics predictive of death within 30 days of diagnosis

\begin{tabular}{|c|c|c|c|c|}
\hline Characteristic & Odds ratio & $95 \%$ & $\begin{array}{l}\text { dence } \\
\text { al }\end{array}$ & $P$-value \\
\hline \multicolumn{5}{|l|}{ Age group } \\
\hline$<65$ & 1.00 & & & \\
\hline $65-74$ & 2.50 & 1.28 & 4.89 & 0.007 \\
\hline $75-79$ & 5.41 & 2.76 & 10.60 & $<0.001$ \\
\hline $80-84$ & 11.13 & 5.78 & 21.43 & $<0.001$ \\
\hline $85+$ & 15.92 & 8.15 & 31.07 & $<0.001$ \\
\hline \multicolumn{5}{|l|}{ SIMD fifth } \\
\hline I-Least deprived & 1.00 & & & \\
\hline 2 & 1.22 & 0.97 & 1.55 & 0.095 \\
\hline 3 & 1.43 & 1.14 & 1.79 & 0.002 \\
\hline 4 & 1.34 & 1.07 & 1.69 & 0.01 \\
\hline 5-Most deprived & 1.16 & 0.92 & 1.46 & 0.204 \\
\hline \multicolumn{5}{|c|}{ Previous inpatient bed days } \\
\hline 0 & 1.00 & & & \\
\hline $1-7$ & 0.81 & 0.67 & 0.98 & 0.026 \\
\hline $8-28$ & 0.87 & 0.72 & 1.05 & 0.135 \\
\hline $29+$ & 0.96 & 0.78 & 1.17 & 0.669 \\
\hline \multicolumn{5}{|c|}{ Previous admission for COPD } \\
\hline No & 1.00 & & & \\
\hline Yes & 1.46 & 1.17 & 1.84 & 0.001 \\
\hline \multicolumn{5}{|c|}{ Previous alcohol-related admission } \\
\hline No & 1.00 & & & \\
\hline Yes & 1.59 & 1.19 & 2.12 & 0.002 \\
\hline
\end{tabular}

Emergency admissions within

30 days of diagnosis date

0

$\geqslant 1$

1.00

9.41

5.45

16.25

$<0.00$

Microscopically verified

Yes

1.00

No

Not known

8.43

4.92

14.45

$<0.00$ ।

umour sub-site

Proximal colon

Distal colon

Rectum/rectosigmoid

Not known

1.00

1.25

1.11

\subsection{4}

0.92

1.80

1.50

1.35

2.67

0.02

0.272

$<0.001$

Dukes' stage

A or B

C

D

Not known

1.00

1.48

1.71

1.12

1.26

0.98

1.94

2.32

1.84

0.006

0.001

Tumour grade

I-II

III-IV

1.00

Not known

1.50

1.48

1.20

1.22

1.88

1.79

$<0.00$ I

$<0.00$ I

Any treatment within

30 days of diagnosis

\begin{tabular}{lllll} 
Yes & 1.00 & & & \\
No & 0.17 & 0.08 & 0.38 & $<0.00$ । \\
\hline
\end{tabular}

Abbreviations: $\mathrm{COPD}=$ chronic obstructive pulmonary disease; SIMD $=$ Scottish index of multiple deprivation. Interaction terms age $\times$ emergency admissions, age $\times$ microscopic verification, age $\times$ any treatment, and Dukes' stage $\times$ any treatment were included in the model.

death other than breast cancer. Patients dying early from colorectal cancer had similar characteristics but in addition were more likely to have had a previous admission for COPD, and more likely to 
have had a previous alcohol-related admission. In contrast to patients with breast cancer, they were more likely to have had treatment within 30 days of diagnosis, at least for disease stages A-C, perhaps reflecting the fact that they had presented acutely with complications of their tumour, such as obstruction or peritonitis, and required urgent surgery. However, it may be unwise to draw definite conclusions about the relationship between treatment and outcome from these observational data. Of the patients with colorectal cancer dying within 30 days, just over $27 \%$ were recorded as having an underlying cause of death other than colorectal cancer. Patients dying early after a diagnosis of breast or colorectal cancer were less likely to follow a conventional pathway to diagnosis - for example, their first relevant admission to hospital was less likely to be under the care of a surgeon.

Our 'control' group included some patients who will have survived just a few days longer than our 'cases'. Had we been able to compare the characteristics of patients dying early with a selected group of longer-term survivors, the differences that we observed would most likely have been accentuated considerably.

The limited impact of socioeconomic position on early deaths was unexpected, but may reflect limitations of the area-based Scottish Index of Multiple Deprivation as an indicator of individual status, and the fact that a high proportion of early deaths occurred in the very elderly, in an age range less commonly attained by people from deprived communities in which life expectancy is lower than average. Similarly, failure to show a clear effect of previous in-patient bed days may reflect better-than-average health of individuals who survive beyond the age of 85 years, as well as inclusion of related covariates, such as previous admissions for COPD, previous alcoholrelated admissions, and emergency admissions in the model.

There is certainly evidence from other studies that some patients present themselves for the first time many weeks or months after the onset of relevant symptoms, and some of the reasons for prehospital delays have been identified (Macleod et al, 2009). Awareness of cancer warning signs appears to be low in Britain, particularly in those who are males, younger, and from lower socioeconomic status groups or ethnic minorities, and there are a number of perceived barriers for consulting (Robb et al, 2009). There is some amount of evidence that interventions delivered to individuals may increase cancer awareness and that interventions delivered to communities may promote awareness and early presentation (Austoker et al, 2009). However, it is of course also important to monitor potential adverse effects of any interventions, such as overwhelming diagnostic services.

At the same time, evidence that delays are associated with more advanced disease stage or lower survival is inconsistent and sometimes counterintuitive. It seems that some patients with aggressive, poor prognosis disease are more likely to present quickly and to be fast-tracked by health services. In fact, the paradox of patients with prolonged duration of symptoms, but who have a better prognosis than patients with shorter duration of symptomatic disease, was highlighted many years ago (Feinstein, 1964). Even then, it was recognised that some patients with longer clinical histories probably had tumours that were biologically less aggressive.

\section{REFERENCES}

Aspinwall LG, MacNamara A (2005) Taking positive changes seriously. Cancer 104(11 Suppl): 2549-2556

Austoker J, Bankhead C, Forbes LJL, Atkins L, Martin F, Robb K, Wardle J, Ramirez AJ (2009) Interventions to promote cancer awareness and early presentation: systematic review. Br J Cancer 101: S31-S39

Department of Health (2007) Cancer Reform Strategy. DoH: London

El-Tamer MB, Ward BM, Schifftner T, Neumayer L, Khuri S, Henderson W (2007) Morbidity and mortality following breast cancer surgery in women: national benchmarks for standards of care. Ann Surg 245: 665-671
Unfortunately, studies on the impact of delay on outcome suffer from a number of limitations, including differing definitions of delays, differing ways of measuring delays, failure to take account of aggressiveness of tumours, failure to allow for emergency admissions (particularly relevant for colon cancer), and failure to take account of lead-time bias (Neal, 2009). Thus, although there may be inevitability about presentation with advanced disease for some individuals, this should not be used to defend avoidable delays faced by other patients living with the anxiety that they may (or do) have cancer.

One further avenue of research that might yield insights is the impact of lifestyle factors on survival from (as opposed to risk of) cancer. The calculation of relative survival can allow for competing causes of death associated with lifestyle factors, but cannot adjust fully for direct effects of these factors on cancer prognosis. For some cancers, there is evidence that smoking is associated with more advanced stage of disease at diagnosis, although it is not clear whether this reflects a difference in health-seeking behaviour or a direct effect of tobacco on tumour biology (Longnecker et al, 1989; Kobrinsky et al, 2003). Furthermore, there is evidence that smoking and some other lifestyle factors reduce the effectiveness of a range of treatments, including surgery, radiotherapy, and chemotherapy (Gritz et al, 2005; Gritz and Demark-Wahnefried, 2009), and smoking has been shown to have an independently adverse impact on cause-specific survival in patients who have had resections for colorectal cancer (Munro et al, 2006). We have been unable to find data on the prevalence of continuous active smoking among patients with cancer in different countries; however, whereas estimates of overall adult smoking prevalence are considerably lower in Sweden than in Scotland (Scottish Public Health Observatory, 2010), estimates for other Nordic countries are more similar to Scotland, suggesting that smoking is unlikely to be the sole explanation for the reported survival deficit in Scotland. For operable patients, there is evidence that both smoking and alcohol abuse increase the risk of postoperative complications, and there is also some evidence that intensive presurgical interventions aimed at addressing these risk factors can improve outcomes (Tønnesen et al, 2009). Obesity and lack of physical activity also seem likely to increase the risks associated with surgery and tackling these problems in the interval between diagnosis and surgery might have a role in reducing the risk of early death. There is also emerging evidence that personality type, mental well-being, and resilience may influence outcomes, and these factors may also be important influences on early mortality (Aspinwall and MacNamara, 2005; Mackenbach, 2010).

In conclusion, we have shown that patients dying within 30 days of a diagnosis of breast or colorectal cancer have many unfavourable prognostic characteristics. Further research is required to determine the mechanisms through which these effects are mediated and, more particularly, whether interventions aimed at dealing with them can improve survival.

\section{Conflict of interest}

The authors declare no conflict of interest.
Engholm G, Kejs AM, Brewster DH, Gaard M, Holmberg L, Hartley R, Iddenden R, Møller $\mathrm{H}$, Sankila R, Thomson CS, Storm HH (2007) Colorectal cancer survival in the Nordic countries and the United Kingdom: excess mortality risk analysis of 5 year relative period survival in the period 1999 to 2000. Int J Cancer 121: $1115-1122$

Feinstein AR (1964) Symptomatic patterns, biologic behavior, and prognosis in cancer of the lung. Practical application of Boolean algebra and clinical taxonomy. Ann Intern Med 61: 27-43 
Gritz ER, Demark-Wahnefried W (2009) Health behaviors influence cancer survival. J Clin Oncol 27: 1930-1932

Gritz ER, Dresler C, Sarna L (2005) Smoking, The Missing Drug Interaction in Clinical Trials: Ignoring the Obvious. Cancer Epidemiol Biomarkers Prev 14: 2287-2293

Holmberg L, Sandin F, Bray F, Richards M, Spicer J, Lambe M, Klint A, Peake M, Strand TE, Linklater K, Robinson D, Møller H (2010) National comparisons of lung cancer survival in England, Norway and Sweden 2001 -2004: differences occur early in follow-up. Thorax 65: 436-441

Information Services Division (2007) NHS Hospital Data Quality: Towards Better Data From Scottish Hospitals. An Assessment of SMR01 and Associated Data 2004 - 2006. ISD Scotland Publications (NHS National Services Scotland): Edinburgh. Available at: http://www.isdscotland.org/ isd/mdq-data-quality-services.jsp?pContentID $=2700 \&$ p_applic $=$ CCC \&p_service $=$ Content.show\& $($ Accessed 21 July 2010)

Kendrick S, Clarke J (1993) The Scottish record linkage system. Health Bull (Edinb) 51: $72-79$

Kobrinsky NL, Klug MG, Hokanson PJ, Sjolander DE, Burd L (2003) Impact of smoking on cancer stage at diagnosis. J Clin Oncol 21: 907-913

Longnecker MP, Clapp RW, Sheahan K (1989) Associations between smoking status and stage of colorectal cancer at diagnosis in Massachusetts between 1982 and 1987. Cancer 64: 1372-1374

Mackenbach JP (2010) New trends in health inequalities research: now it's personal. Lancet 376: 854-855

MacLennan R (1991) Chapter 6: Items of patient information which may be collected by registries. In Cancer Registration Principles and Methods, Jensen OM, Parkin DM, MacLennan R, Muir CS, Skeet RG (eds). pp 43-63. IARC Scientific Publications No. 95. International Agency for Research on Cancer: Lyon

Macleod U, Mitchell ED, Burgess C, Macdonald S, Ramirez AJ (2009) Risk factors for delayed presentation and referral of symptomatic cancer: evidence for common cancers. Br J Cancer 101: S92-S101
Møller H, Sandin F, Bray F, Klint A, Linklater KM, Purushotham A Robinson D, Holmberg L (2010) Breast cancer survival in England, Norway and Sweden: A population-based comparison. Int J Cancer 127(11): $2630-2638$

Munro AJ, Bentley AHM, Ackland C, Boyle PJ (2006) Smoking compromises cause-specific survival in patients with operable colorectal cancer. Clin Oncol 18: 436-440

Neal RD (2009) Do diagnostic delays matter? Br J Cancer 101: S9-S12

Robb K, Stubbings S, Ramirez A, Macleod U, Austoker J, Waller J, Hiom S, Wardle J (2009) Public awareness of cancer in Britain: a populationbased survey of adults. Br J Cancer 101: S18-S23

Sant M, Allemani C, Santaquilani M, Knijn A, Marchesi F, Capocaccia R, EUROCARE Working Group (2009) EUROCARE-4. Survival of cancer patients diagnosed in 1995-1999. Results and commentary. Eur J Cancer 45: $931-991$

Scottish Government (2006) http://www.scotland.gov.uk/Publications/2006/ 10/13142739/0 (accessed 10 August 2010)

Scottish Public Health Observatory (2010) Tobacco use: adult European comparison. Available at: http://www.scotpho.org.uk/home/Behaviour/ Tobaccouse/tobacco_data/tobacco_adulteuro.asp (accessed 3 August 2010)

Tekkis PP, Poloniecki JD, Thompson MR, Stamatakis JD (2003) Operative mortality in colorectal cancer: prospective national study. BMJ 327: $1196-1201$

Thompson AM, Stonebridge PA (2005) Building a framework for trust: critical event analysis of deaths in surgical care. BMJ 330 $1139-1142$

Thomson CS, Forman D (2009) Cancer survival in England and the influence of early diagnosis: what can we learn from recent EUROCARE results? Br J Cancer 101(Suppl 2): S102-S109

Tønnesen H, Nielsen PR, Lauritzen JB, Møller AM (2009) Smoking and alcohol intervention before surgery: evidence for best practice. $\mathrm{Br} J$ Anaesth 102: 297-306

Appendix 1. Diagnostic codes used to identify hospital admissions with chronic obstructive pulmonary disease (COPD) and alcohol-related diagnoses

\begin{tabular}{lll}
\hline ICD-9 code & ICD-10 code & Condition \\
\hline COPD & & \\
490 & $\mathrm{~J} 40$ & Bronchitis, not specified as acute or chronic \\
& $\mathrm{j} 41$ & Simple and mucopurulent chronic bronchitis \\
491 & $\mathrm{j} 42$ & Unspecified chronic bronchitis \\
492 & $\mathrm{~J} 43$ & Emphysema \\
496 & $\mathrm{j} 44$ & Other COPD
\end{tabular}

\section{Alcohol-related diagnoses}

$\begin{array}{ll} & \mathrm{E} 244 \\ 291 & \mathrm{E} 512 \\ 303 & \mathrm{~F} 10 \\ & \mathrm{G} 312 \\ 3575 & \mathrm{G} 621 \\ & \mathrm{G} 721 \\ 4255 & \mathrm{1} 262 \\ 5353 & \mathrm{~K} 292 \\ 5710 & \mathrm{~K} 70 \\ 5711 & \\ 5712 & \\ 5713 & \\ & \mathrm{~K} 860 \\ & \mathrm{O} 354 \\ 7903 & \mathrm{R} 780 \\ 9800 & \mathrm{~T} 510 \\ 9801 & \mathrm{~T} 511 \\ 3050 & \mathrm{~T} 19 \\ 9809 & \\ \mathrm{E} 860 & \times 45 \\ & \times 65 \\ & \mathrm{Y} 15\end{array}$

Alcohol-induced Pseudo-Cushing's syndrome

Wernicke's encephalopathy

Mental and behavioural disorders due to use of alcohol

Degeneration of nervous system due to alcohol

Alcoholic polyneuropathy

Alcoholic myopathy

Alcoholic cardiomyopathy

Alcoholic gastritis

Alcoholic liver disease

Alcohol-induced chronic pancreatitis

Maternal care for (suspected) damage to fetus from alcohol

Finding of alcohol in blood

Toxic effect of ethanol

Toxic effect of methanol

Toxic effect of alcohol, unspecified

Accidental poisoning by and exposure to alcohol

Intentional self-poisoning by and exposure to alcohol

Poisoning by and exposure to alcohol undetermined intent 
Early deaths after breast or colorectal cancer in Scotland

DH Brewster et al

Appendix I. (Continued)

E9473
Alcohol deterrents

Evidence of alcohol involvement determined by blood alcohol level Evidence of alcohol involvement determined by level of intoxication

Alcohol rehabilitation

Alcohol abuse counselling and surveillance

Alcohol use 